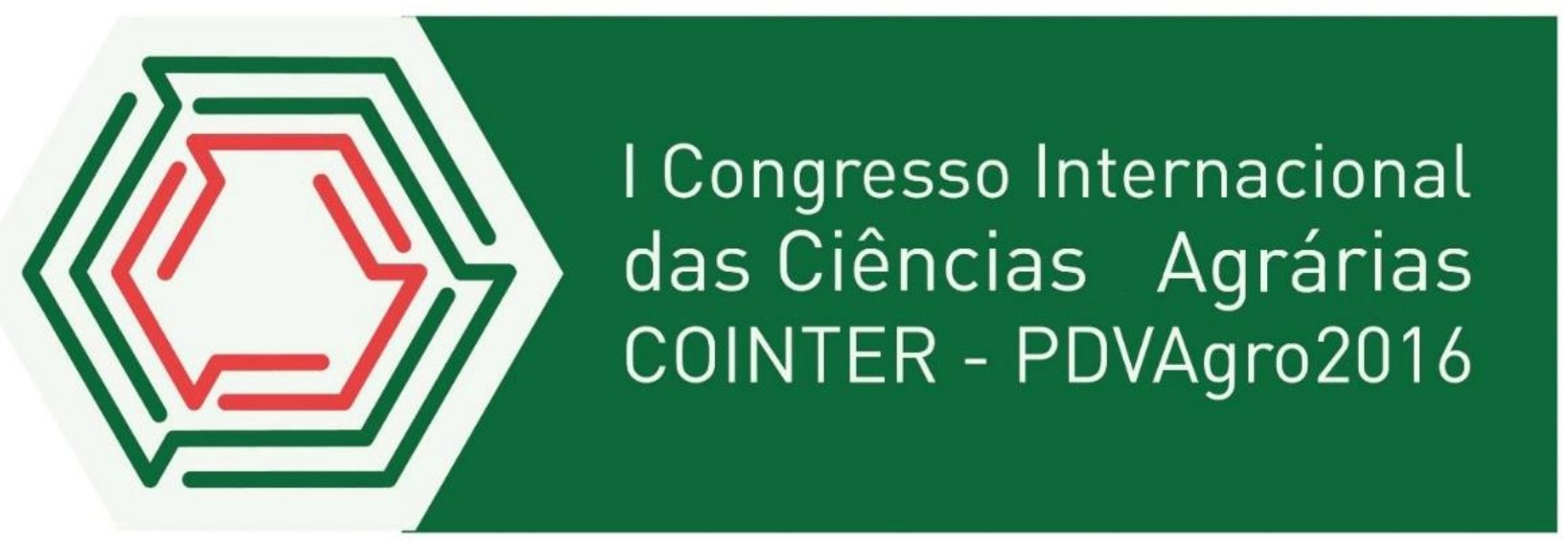

\title{
POTENCIAL ENERGÉTICO DE GRAMÍNEAS NO POLO GESSEIRO DO ARARIPE EM PERNAMBUCO.
}

Apresentação: Pôster

Wellisson José Maurício De Andrade ${ }^{(1)}$; Renato Lemos Do Santos ${ }^{(2)}$; Rafaela Muniz Barbosa ${ }^{(1)}$; Fernando José Freire ${ }^{(3)}$; Emídio Cantídio Almeida de Oliveira ${ }^{(3)}$; Ruthanna Isabelli de Oliveira ${ }^{(4)}$.

\section{Introdução}

A cana (Saccharum spp.) e o capim elefante (Pennisetum purpureum Schum) são plantas possuidoras do metabolismo $\mathrm{C} 4$, que possui uma alta taxa fotossintética pela unidade de área. As deficiências nutricionais limitam a produção de cana e de capim elefante associadas a fatores relacionados com acidez do solo, particularmente toxidez de $\mathrm{Al}$, baixa disponibilidade de $\mathrm{Ca}$ e $\mathrm{Mg}$ e deficiência de P. A calagem é a prática mais eficiente em superfície. Para atingir camadas inferiores a superficial recomenda-se gessagem, para a correção de teores tóxicos de $\mathrm{Al}$ ou para a elevação do teor de $\mathrm{Ca}$. O objeto é avaliar o efeito do gesso mineral no potencial energético de diferentes genótipos de cana e de capim elefante na Chapada do Araripe em Pernambuco. O trabalho foi realizado na Estação Experimental do Instituto Agronômico de Pernambuco (IPA), no município de Araripina/PE. Foram utilizadas três variedades de cana, duas energéticas (C90-176 e C90-178) e uma açucareira (RB962962), e duas variedades de capim elefante (Cameron e Venezuela), submetidas a duas doses de gesso minerado, 0 e $0,6 \mathrm{t}$ ha- 1 , com 4 repetições. O teor de FDA nas folhas, colmo e parte aérea das gramíneas variou entre os genótipos pela aplicação de gesso. A aplicação do gesso não alterou o teor de FDN e lignina nos compartimentos estudados.

\section{Fundamentação Teórica}

A cana (Saccharum spp.) e o capim elefante (Pennisetum purpureum Schum) são plantas possuidoras do metabolismo $\mathrm{C} 4$, consideradas altamente eficientes na conversão de energia proveniente do sol em química, ou seja, são espécies vegetais de grande capacidade acumulativa de 
${ }^{1}$ Estudante de Agronomia do Instituto Federal de Educação, Ciência e Tecnologia de Pernambuco-(IFPE) - campus Vitória de Santo Antão - PE.wellisson.andrade2@gmail.com;

${ }^{2}$ Professor do Instituto Federal de Educação, Ciência e Tecnologia de Pernambuco-(IFPE) - campus Vitória de Santo Antão - PE;

${ }^{3}$ Professor da Universidade Federal Rural de Pernambuco;

${ }^{4}$ Doutora em ciência do solo.

biomassa, inclusive pela sua elevada taxa fotossintética por unidade de área (ALBUQUERQUE, 2013).

A elevada capacidade de produção de matéria seca credencia a cana e o capim elefante como biomassas alternativas para produção de energia no Polo Gesseiro do Araripe, que utiliza a vegetação nativa do bioma Caatinga para calcinação de gipsita sem manejo florestal (ALBUQUERQUE, 2013; SANTOS, 2011).

Entretanto, para que a cana e o capim elefante desenvolvam o potencial de produção de biomassa, necessita-se do fornecimento de nutrientes e de água em níveis adequados, e em equilíbrio com a necessidade. Por isso, se faz crucial pesquisar as relações nutricionais de genótipos de cana e de capim elefante na região do Araripe.

As deficiências nutricionais limitantes ao estabelecimento e produção de cana e de capim elefante têm sido associadas a fatores relacionados com acidez do solo, particularmente toxidez de $\mathrm{Al}$, baixa disponibilidade de $\mathrm{Ca}$ e Mg e deficiência de P (QUESADA, 2005; ALBUQUERQUE, 2013). Nesse contexto, está concentrado grande parte dos solos descritos na Chapada do Araripe. Em geral são Latossolos que apresentam limitações agrícolas pelos elevados índices de acidez, tanto em superfície como em subsuperfície (CAVALCANTI \& LOPES, 1994).

Para corrigir essa acidez em subsuperfície recomenda-se a gessagem (SUMNER et al., 1986). O uso do gesso produzido na própria região do Araripe pode potencializar a produção de matéria seca dos genótipos de cana e de capim elefante, por sua atuação na correção da acidez trocável em subsuperfície, proporcionando maior quantidade de biomassa que pode ser utilizada como fonte de energia alternativa no processo de calcinação da gipsita na indústria gesseira do Araripe.

Desta forma, neste trabalho objetiva-se avaliar o efeito do gesso mineral no potencial energético de diferentes genótipos de cana e de capim elefante na Chapada do Araripe em Pernambuco.

\section{Metodologia}

O trabalho foi realizado na Estação Experimental do Instituto Agronômico de Pernambuco (IPA), no município de Araripina/PE no período de fevereiro de 2014 a janeiro de 2015, em um LATOSSOLO VERMELHO-AMARELO distrófico (CAVALCANTI \& LOPES, 1994).

Foram utilizadas três variedades de cana, duas energéticas (C90-176 e C90-178) e uma açucareira (RB962962), e duas variedades de capim elefante (Cameron e Venezuela), submetidas a duas doses de gesso minerado, 0 e $0,6 \mathrm{t} \mathrm{ha}^{-1}$, com base na necessidade de calagem nas profundidades de 0,2-0,4 e 0,4-0,6 m, compondo o arranjo fatorial 5 x 2 . O ensaio foi disposto em delineamento de blocos casualizados utilizando-se quatro repetições. Cada parcela foi composta por cinco sulcos de $10 \mathrm{~m}$ de comprimento, espaçados de $1 \mathrm{~m}$, perfazendo uma área total de $50 \mathrm{~m}^{2}$. A área útil foi formada pelas três linhas centrais, descartando $1 \mathrm{~m}$ das extremidades, o que totalizou 24 $\mathrm{m}^{2}$.

Para caracterizar o solo química e fisicamente foram realizadas coletas de solo nas profundidades de 0,0-0,2; 0,2-0,4 e 0,4-0,6 m. Quimicamente o solo foi caracterizado pelo $\mathrm{pH}$ $\left(\mathrm{H}_{2} \mathrm{O}\right), \mathrm{Ca}^{2+}, \mathrm{Mg}^{2+}, \mathrm{K}^{+}, \mathrm{Na}^{+}, \mathrm{Al}^{3+},(\mathrm{H}+\mathrm{Al}), \mathrm{P}$ e Carbono Orgânico Total (EMBRAPA, 2009); e o $\mathrm{SO}_{4}{ }^{2-}$, de acordo com a metodologia descrita por Alvarez et al. (2001). Com os dados obtidos foi 
ainda calculada a capacidade de troca de cátions efetiva, a saturação por alumínio e a saturação por bases.

Fisicamente o solo foi caracterizado de acordo com sua granulometria, para definição de sua classe textural, sendo determinada pelo método da pipeta adaptado por Ruiz (2005). Realizou-se ainda, análises de densidade do solo e densidade de partículas pelo método da proveta e do balão volumétrico respectivamente, por fim porosidade total (EMBRAPA, 1997).

A instalação do experimento foi iniciada em 15 de janeiro de 2014, com a distribuição a lanço e incorporação de calcário dolomítico com grade de disco até $0,2 \mathrm{~m}$ de profundidade. A necessidade de calagem foi de $0,3 \mathrm{t} \mathrm{ha}^{-1}$, calculada pelo método da saturação por bases (ALVAREZ \& RIBEIRO, 1999).

Em 28 de fevereiro de 2014 foi realizado o plantio das variedades de cana e capim elefante. Foram abertos sulcos de $0,2 \mathrm{~m}$ de profundidade, onde foram distribuídos os propágulos vegetativos: $14 \mathrm{t} \mathrm{ha}^{-1}$ de colmos de cana e $4 \mathrm{t} \mathrm{ha}^{-1}$ de colmos de capim elefante, sendo dispostos nos sulcos como corrente dupla, de modo que a ponta de uma coincidisse com a base da outra. Posteriormente, os colmos de ambas as espécies vegetais foram rebolados em toletes com 4 a 5 gemas, e em seguida o fechamento do sulco.

As adubações de $\mathrm{N}$ e $\mathrm{K}$ foram realizadas de acordo com as recomendações de adubação para o estado de Pernambuco (IPA, 2008) e a adubação de P de acordo com Simões Neto (2008). Com os resultados das análises química da caracterização do solo foram aplicadas em todas as parcelas $136 \mathrm{~kg} \mathrm{ha}^{-1}$ de ureia (44\% de N), $440 \mathrm{~kg} \mathrm{ha}^{-1}$ de superfosfato triplo $\left(41 \%\right.$ de $\left.\mathrm{P}_{2} \mathrm{O}_{5}\right)$ e $121 \mathrm{~kg} \mathrm{ha}^{-1} \mathrm{de}$ cloreto de potássio ( $58 \%$ de $\mathrm{K}_{2} \mathrm{O}$ ). Para o $\mathrm{N}$ e o K, $1 / 3$ foi aplicado em fundação e $2 / 3$ em cobertura, aos 70 dias após o plantio (DAP).

A avaliação de variáveis energéticas nas diferentes variedades de cana e capim elefante foi efetivada aos 320 dias após o plantio (DAP). Foram coletadas 3 plantas aleatoriamente na parcela útil, separadas em colmo, folhas, parte aérea (colmo e folhas), sendo posteriormente pesadas, trituradas em forrageira. Em seguida retirada uma subamostra, que também teve seu peso registrado, sendo seca em estufa de circulação forçada de ar a $65^{\circ} \mathrm{C}$. Após secagem, as amostras de biomassa foram trituradas em moinho de facas com peneira de malha de $1 \mathrm{~mm}$ de diâmetro, a fim de se proceder as determinações os teores de fibra em detergente neutro (FDN), fibra em detergente ácido (FDA) e lignina, de acordo com Van Soest \& Wine (1968).

As variáveis foram submetidas à análise da variância pelo teste $\mathrm{F}(\mathrm{p}<0,05)$ em função dos genótipos e das doses de gesso. Nas variáveis em que observaram efeitos significativos, foi aplicado o teste de comparação de médias de Scott $\operatorname{Knott}(\mathrm{p}<0,05)$.

\section{Resultados e Discussões}

O teor de FDA nas folhas, colmo e parte aérea das gramíneas variou entre os genótipos pela aplicação de gesso (Tabela 1). A aplicação de gesso promoveu aumento no teor de FDA em todos os genótipos, exceto na C90-178, que não variou. Quando se compara os genótipos em cada dose de gesso, se observa, na ausência do insumo, o maior valor de FDA na C90-178, não se diferenciado dos demais com a aplicação de gesso.

No compartimento colmo, os teores de FDA dos genótipos foram diferentes entre si, independente da aplicação de gesso, tendo os capins apresentado os maiores valores, sendo maior no Cameron (Tabela 1). Nesse compartimento, a aplicação de gesso não alterou os valores de FDA dos genótipos, exceto do Venezuela, que teve seu teor reduzido em $13 \%$.

$\mathrm{Na}$ componente parte aérea, a aplicação de gesso reduziu o teor de FDA no capim Venezuela e aumentou na RB922962 (Tabela 1). Tanto na ausência quanto na presença do gesso o 
teor de FDA nos genótipos diferiu, tem apresentado maiores valores o capim Cameron e a cana C90-178.

Os teores de FDN em todos os compartimentos avaliados (folha, colmo e parte aérea), não variação em função da aplicação de gesso, entretanto, diferiram entre os genótipos (Tabela 1). Na folha, entre os genótipos, os de cana foram semelhantes entre si, alcançando os maiores teores, diferenciando-se dos capins, que entre si foram semelhantes. No órgão vegetativo colmo, o cultivar Cameron destacou-se com o maior teor de FDN e diferenciou dos demais, embora, as canas energéticas (C90-176 e C90-178) tenham sido semelhantes diferenciando dos demais genótipos. Na parte aérea, também foi encontrado o maior teor de FDN no capim Venezuela, sendo seguido das canas energéticas. O menor valor de FDN foi encontrado na RB922962.

Nos três compartimentos avaliados os teores de lignina independeram das doses de gesso (Tabela 1). Nas folhas, entre os genótipos avaliados, o Cameron apresentou o menor teor de lignina na folha. Já nos compartimentos colmo e parte aérea, os teores apresentaram comportamentos iguais, onde, o cultivar Cameron teve o maior valor quanto a lignina, diferindo dos demais, e as canas energéticas foram semelhantes com os menores valores, sendo ainda, diferentes dos demais.

Tabela 1. Fibra em detergente ácido, fibra em detergente neutro e lignina na folha, colmo e parte aérea em diferentes fontes de energia de biomassa (gramíneas) na presença e ausência de gesso agrícola mineral aos 320 dias após o plantio, média, análise de variância e coeficiente de variação dos dados.

\begin{tabular}{|c|c|c|c|c|c|c|c|c|c|}
\hline \multirow{2}{*}{ Gramíneas } & \multicolumn{2}{|c|}{ FDA } & \multirow{2}{*}{ Média } & \multicolumn{2}{|c|}{ FDN } & \multirow{2}{*}{ Média } & \multicolumn{2}{|c|}{ Lignina } & \multirow{2}{*}{ Média } \\
\hline & C/Gesso & S/Gesso & & C/Gesso & S/Gesso & & C/Gesso & S/Gesso & \\
\hline & & & & & Folha & & & & \\
\hline C90-176 $6^{(1)}$ & $37,06 \mathrm{aA}$ & $36,27 \mathrm{aB}$ & 36,67 & 72,67 & 72,42 & $72,55 \mathrm{a}$ & 4,08 & 4,11 & $4,09 \mathrm{a}$ \\
\hline C90-178 $(1)$ & $37,08 \mathrm{aA}$ & $36,90 \mathrm{aA}$ & 36,99 & 72,50 & 71,84 & $72,17 \mathrm{a}$ & 4,15 & 4,40 & $4,28 \mathrm{a}$ \\
\hline RB96292(2) & $36,04 \mathrm{bA}$ & $35,16 \mathrm{bB}$ & 35,60 & 72,91 & 71,85 & $72,38 \mathrm{a}$ & 4,05 & 4,14 & $4,10 \mathrm{a}$ \\
\hline Cameron $^{(3)}$ & $29,94 \mathrm{dA}$ & $29,11 \mathrm{~dB}$ & 29,52 & 65,34 & 66,03 & $65,69 \mathrm{~b}$ & 3,17 & 2,76 & $2,97 b$ \\
\hline Venezuela $^{(3)}$ & $33,62 \mathrm{cA}$ & $31,07 \mathrm{cB}$ & 32,34 & 66,24 & 65,04 & $65,64 b$ & 3,96 & 3,50 & $3,73 \mathrm{a}$ \\
\hline \multirow[t]{2}{*}{ Média } & 34,75 & 33,70 & & 69,93 & 69,44 & & 3,88 & 3,78 & \\
\hline & & $\mathrm{F}$ & & & $\mathrm{F}$ & & & $\mathrm{F}$ & \\
\hline Gramíneas & & $336,60 * *$ & & & $161,82 * *$ & & & $12,72 * *$ & \\
\hline Gesso & & $44,90 * *$ & & & $3,67 \mathrm{~ns}$ & & & $0,58 \mathrm{~ns}$ & \\
\hline Gram*Ges & & $6,44 * *$ & & & $1,72 \mathrm{~ns}$ & & & $1,16 \mathrm{~ns}$ & \\
\hline \multirow[t]{2}{*}{ C.V. $(\%)$} & 1,44 & & & 1,17 & & & 10,84 & & \\
\hline & & & & & Colmo & & & & \\
\hline C90-176 & $36,76 \mathrm{dA}$ & $36,49 \mathrm{dA}$ & 36,62 & 65,53 & 65,88 & $65,71 c$ & 4,21 & 4,07 & $4,14 d$ \\
\hline C90-178 & $39,09 \mathrm{cA}$ & $38,89 \mathrm{cA}$ & 38,99 & 65,24 & 64,92 & $65,08 \mathrm{c}$ & 3,68 & 3,87 & $3,77 d$ \\
\hline RB96292 & $30,74 \mathrm{eA}$ & $30,35 \mathrm{eA}$ & 30,54 & 56,78 & 56,74 & $56,76 \mathrm{~d}$ & 4,76 & 4,72 & $4,74 \mathrm{c}$ \\
\hline Cameron & $47,51 \mathrm{aA}$ & $48,02 \mathrm{aA}$ & 47,77 & 77,05 & 77,49 & $77,27 \mathrm{a}$ & 10,01 & 9,91 & $9,96 a$ \\
\hline Venezuela & $40,62 \mathrm{bB}$ & $46,73 \mathrm{bA}$ & 43,68 & 67,70 & 70,48 & $69,09 \mathrm{~b}$ & 6,89 & 6,43 & $6,66 b$ \\
\hline \multirow[t]{2}{*}{ Média } & 38,94 & 40,09 & & 66,46 & 67,10 & & 5,91 & 5,80 & \\
\hline & & F & & & F & & & $\mathrm{F}$ & \\
\hline Gramíneas & & $785,36^{* *}$ & & & $385,49 * *$ & & & $188,31 * *$ & \\
\hline Gesso & & $29,73 * *$ & & & 3,60ns & & & $0,44 \mathrm{~ns}$ & \\
\hline Gram*Ges & & $35,11 * *$ & & & $2,67 \mathrm{~ns}$ & & & $0,39 \mathrm{~ns}$ & \\
\hline C.V.(\%) & 1,69 & & & 1,60 & & & 8,98 & & \\
\hline
\end{tabular}




\begin{tabular}{|c|c|c|c|c|c|c|c|c|c|}
\hline C90-176 & $36,91 \mathrm{cA}$ & $36,38 \mathrm{cA}$ & 36,64 & 69,10 & 69,15 & $69,13 b$ & 4,15 & 4,09 & $4,12 \mathrm{~d}$ \\
\hline C90-178 & $38,09 \mathrm{bA}$ & $37,89 \mathrm{bA}$ & 37,99 & 68,87 & 68,38 & $68,62 b$ & 3,91 & 4,14 & $4,02 \mathrm{~d}$ \\
\hline RB96292 & $33,39 \mathrm{dA}$ & $32,75 \mathrm{~dB}$ & 33,07 & 64,85 & 64,29 & $64,57 d$ & 4,41 & 4,43 & $4,42 \mathrm{c}$ \\
\hline Cameron & $38,73 \mathrm{aA}$ & $38,56 \mathrm{aA}$ & 38,64 & 71,20 & 71,76 & $71,48 \mathrm{a}$ & 6,59 & 6,34 & $6,46 a$ \\
\hline Venezuela & $37,12 \mathrm{cB}$ & $38,90 \mathrm{aA}$ & 38,01 & 66,97 & 67,76 & $67,37 \mathrm{c}$ & 5,43 & 4,97 & $5,20 \mathrm{~b}$ \\
\hline \multirow[t]{2}{*}{ Média } & 36,84 & 36,90 & & 68,20 & 68,27 & & 4,90 & 4,79 & \\
\hline & & $\mathrm{F}$ & & & $\mathrm{F}$ & & & $\mathrm{F}$ & \\
\hline Gramíneas & & $273,50 * *$ & & & $101,19 * *$ & & & $110,35^{* *}$ & \\
\hline Gesso & & $0,18 \mathrm{~ns}$ & & & $0,11 \mathrm{~ns}$ & & & $1,47 \mathrm{~ns}$ & \\
\hline Gram*Ges & & $13,22 * *$ & & & $1,44 \mathrm{~ns}$ & & & $1,83 \mathrm{~ns}$ & \\
\hline C.V.(\%) & 1,04 & & & 1,04 & & & 5,64 & & \\
\hline
\end{tabular}

\section{Conclusões}

A aplicação do gesso não alterou o teor de FDN e lignina nos compartimentos estudados.

\section{Referências}

ALBUQUERUQE, H.S. Desempenho agroenergético, uso de água e de nutrientes por cana-deaçúcar cultivada na Chapada do Araripe. Dissertação (Mestrado), Universidade Federal Rural de Pernambuco, Serra Talhada. 2013. 71p.

ALVAREZ V, V. H. et al. Uso de gesso agrícola. In: RIBEIRO, A. C.; GUIMARÃES, P. T. G.; ALVAREZ V, V. H. Recomendações para o uso de corretivos e fertilizantes em Minas Gerais $5^{\circ}$ aproximação. Viçosa-MG, 1999.

CAVAlCANTI, A. C.; LOPES, O. F. Condições edafoclimáticas da Chapada do Araripe e viabilidade de produção sustentável de culturas. Embrapa, Centro de Pesquisa Agropecuária do Trópico Semiárido, Unidade de Execução de Pesquisa e Desenvolvimento, Brasília, 41p., 1994.

EMBRAPA. Manual de métodos de análises de solos. $2^{\mathrm{a}}$ ed. Rio de Janeiro: Centro Nacional de Pesquisa de solos, 212p., 1997.

EMBRAPA. Manual de análises químicas de solos, plantas e fertilizantes / editor técnico, Fábio Cesar da Silva. - 2. ed. rev. ampl. - Brasília, DF : Embrapa Informação Tecnológica, 627 p., 2009.

IPA - Empresa Pernambucana de Pesquisa Agropecuária. Recomendações de adubação para o Estado de Pernambuco. Recife, 2a aproximação, 2. ed. rev., IPA, 198p., 2008.

QUESADA, D. M. Parâmetros quantitativos e qualitativos de diferentes genótipos de capim elefante como potencial para uso energético. Tese (Doutorado), Universidade Federal Rural do Rio de Janeiro, Seropédica, 76 p., 2005.

SANTOS, R.L. Capim elefante cultivado em solo ácido com aplicação de gesso com alternativa fitoenergética para o Polo Gesseiro do Araripe-PE. Dissertação (Mestrado), Universidade Federal Rural de Pernambuco, Recife. 2011. 96p. 
SIMÕES NETO, D. E. Avaliação da disponibilidade de fosforo e recomendação de adubação fosfatada para cana-planta em solos do estado de Pernambuco. 2008. 106f. Tese (Doutorado), Universidade Federal Rural de Pernambuco, Recife. 2008. 105p.

SUMNER, M.E. et al. Amelioration of an acid soil profile through deep liming and surface 